\title{
Different Training-Induced Skeletal Muscle Adaptations in COPD Patients with and without Alpha-1 Antitrypsin Deficiency
}

\author{
Inga Jarosch Sebastian Gehlert Daniel Jacko Rembert Andreas Koczulla \\ Marion Wencker Tobias Welte Wilhelm Bloch Sabina Janciauskiene \\ Klaus Kenn \\ Department of Respiratory Medicine, Schön Klinik Berchtesgadener Land, Schönau am Königssee, Germany
}

\section{Key Words}

Skeletal muscle Chronic obstructive pulmonary disease .

Alpha-1 antitrypsin deficiency - Exercise training ·

Pulmonary rehabilitation

\begin{abstract}
Background: Pulmonary rehabilitation (PR) improves oxidative capacity of peripheral muscles in patients with chronic obstructive pulmonary disease (COPD). The exercise-induced oxidative skeletal muscle adaptation in COPD patients with inherited alpha-1 antitrypsin deficiency (A1ATD) has not been studied. Objectives: To compare PR effects on skeletal muscle adaptation in COPD patients with and without A1ATD. Methods: Nine COPD patients with A1ATD (genotype $\mathrm{PiZZ}, 6$ receiving A1AT augmentation therapy), and 10 'usual' COPD patients (genotype PiMM) performed an incremental cycling test and underwent musculus vastus lateralis biopsies before and after a 3-week PR program including exercise training. Results: PiZZ and PiMM patients improved peak work rate following PR $(+9 \pm 11 \mathrm{~W}, \mathrm{p}<0.05$, and $+18 \pm$ $9 \mathrm{~W}, \mathrm{p}<0.001$, between-group difference $\mathrm{p}<0.05)$. PiMM patients increased fibre type I (+8.1\%), reduced fibre type IIA $(-2.1 \%)$ and hybrid fibre type IIA/IIX proportion (-3.9\%). Following PR, PiMM patients also raised mitochondrial signalling proteins PGC-1a (4.5-fold), and TFAM (6.4-fold). PiZZ pa-
\end{abstract}

tients had no change in fibre type I but showed a shift of type IIA/IIX (-8.8\%) towards fibre type IIA distribution (+8.9\%). The capillary to fibre ratio increased by $28 \%(p<0.05)$ in PiZZ, whereas no change was observed in PiMM patients. Linear regression analysis revealed that diffusion capacity and A1 AT therapy are predictor variables for myofibre type I response to PR $\left(r^{2}=0.684, p<0.01\right)$. Conclusions: Following a 3-week PR with comparable training modalities, PiMM but not PiZZ patients increased the oxidative myofibre type I proportion. This skeletal muscle adaptation pattern suggests better improvement of exercise capacity in PiMM than in PiZZ patients with COPD.

(c) 2016 S. Karger AG, Basel

\section{Introduction}

In chronic obstructive pulmonary disease (COPD), a common extra-pulmonary manifestation is skeletal muscle dysfunction, characterised by muscle weakness, atrophy, mitochondrial dysfunction, poor oxidative capacity, and a muscle fibre shift from type I to type II $[1,2]$. Skeletal muscle dysfunction, in addition to other effects such

I.J. and S.G. contributed equally to this work as first co-authors; S.J. and K.K. contributed equally to this work as last co-authors.

\section{KARGER}

E-Mail karger@karger.com

www.karger.com/res
C 2016 S. Karger AG, Basel

0025-7931/16/0925-0339\$39.50/0
Inga Jarosch

Department of Respiratory Medicine, Schön Klinik Berchtesgadener Land Malterhöh 1

DE-83471 Schönau am Königssee (Germany)

E-Mailijarosch@schoen-kliniken.de 
as reduced exercise capacity and quality of life, can significantly impact the survival of COPD patients [3].

Over the last decades, pulmonary rehabilitation (PR) has advanced as a therapeutic option in patients with chronic respiratory diseases [4]. PR, including exercise training as a main component, can partially reverse the morphological and structural abnormalities of peripheral muscle fibres, increase exercise performance and improve quality of life $[4,5]$. Several studies have reported significant improvements in the function, morphology $[2,6]$ and metabolism of skeletal muscle following PR interventions lasting 6 or more weeks [7]. In Germany, PR is usually conducted as an inpatient program with a common duration of 3 weeks $[8,9]$.

A subgroup of COPD patients has an inherited PiZZ (Glu342Lys) alpha-1 antitrypsin deficiency (A1ATD), which is a genetic risk factor for early-onset emphysematous COPD [10]. In the recent literature, solely the Canadian Thoracic Society recommends PR particularly for patients with A1ATD-related COPD [11]. In clinical practice, PR training modalities do not differ between COPD patients with various genotypes. A retrospective analysis indicates that following 3 weeks' inpatient PR training, patients with A1ATD-related COPD improve less in exercise capacity than COPD patients without inherited A1ATD [12]. The reason for this difference remains unknown. Therefore, the aim of the present study was to analyse the effects of a 3-week $\mathrm{PR}$, including a standardised exercise-training program, on peripheral muscle adaptation in COPD patients with and without A1ATD. We hypothesised that lower improvements in exercise capacity in A1ATD patients might be mirrored by defective adaptation in oxidative myofibre type I.

\section{Materials and Methods}

This study was conducted in accordance with the Bavarian Ethics Committee (09010) and registered on clinicaltrials.gov (NCT01380626). All subjects provided informed written consent.

Study Subjects

Nine PiZZ and 10 PiMM COPD patients with non-mutated SERPINA1 gene corresponding to the ' $\mathrm{M}$ ' allele, which produces normal levels of A1AT were included in this prospective trial between February 3, 2010, and January 9, 2013. The exclusion criteria were: (a) disease exacerbation within the last 30 days, (b) acute coronary syndrome, (c) use of anti-coagulant medication, and (d) any disability that inhibited $\mathrm{PR}$ attendance. We asked patients with a stable COPD $\left(\mathrm{FEV}_{1}<50 \%\right.$ pred and a BMI between 20 and 30$)$ to participate if they already were characterised by the PiMM or the PiZZ genotype.

\section{PR Program}

The 3-week exercise training program employed in this study was a component of a comprehensive, multidisciplinary, inpatient PR program [13]. The exercise training program consisted of daily endurance training on a cycle ergometer [ $60 \%$ of peak work rate (PWR)] and resistance training for large muscle groups (3 sets with 20 repetitions). The duration of endurance training was enhanced according to a standardised protocol (10 to $30 \mathrm{~min}$ ); training intensity was increased when Borg values were rated below 4 points (moderate) on a modified Borg scale (0-10).

\section{Diagnostics}

Lung function parameters, including diffusion capacity for carbon monoxide, were measured using a Master Screen Body Plethysmograph (CareFusion, San Diego, Calif., USA) in accordance with current American Thoracic Society (ATS) guidelines [14]. The 6-min walk test, performed according to the ATS guidelines, is the common diagnostic tool in COPD patients to assess exercise capacity [15]. A symptom-limited incremental cycling test was used to determine the PWR and therefore to tailor training intensity. To evaluate the level of physical activity, SenseWear Armband $^{\circledR}$ (BodyMedia, Bad Schönborn, Germany) was worn for 5 consecutive days at the beginning of PR.

\section{Skeletal Muscle Biopsies}

Percutaneous biopsies of the musculus vastus lateralis were obtained prior to the first session and $24 \mathrm{~h}$ after the final session (Bergstrøm-needle), as previously described [16]. Consecutive $7-\mu \mathrm{m}$ cross-sections of muscle biopsies were stained immunohistochemically [15]. Primary antibodies raised against adult human myosin heavy chain type I (A4.951, 1:200), type IIA (SC71, 1:200) and type IIX (6H1, 1:100) were purchased from Developmental Studies Hybridoma Bank (Iowa City, Iowa, USA). Caveolin I antibodies (1:800) (BD Biosciences, San Jose, Calif., USA) were used to stain capillaries. To determine the capillary-to-fibre ratio (CFR), capillary contacts ( $\geq 50$ myofibres per type, subject and time point) were counted in images at 40 -fold magnification. The distribution of type I, IIA, IIX, and hybrid fibres (I/IIA and IIA/IIX) was determined by comparing the specific staining pattern of different myofibre types within all consecutively stained cross-sections. Analyses were carried out blinded and by 2 independent investigators for each data set.

\section{Western Blotting}

Western blotting procedures were conducted as described previously [16]. Briefly, $25 \mathrm{mg}$ of muscle tissue was homogenised with a micro-dismembrator (Braun, Melsungen, Germany) within liquid nitrogen pre-cooled Teflon tubes. Equal amounts of protein $(15 \mu \mathrm{g})$ were separated on a $4-12 \%$ BIS-TRIS Gel using a gel casting system working with MOPS [3-(N-morpholino)propansulfonic acid] electrophoresis buffer. Muscle samples of at least 12 subjects (before and after PR) were loaded on the same gel and separated under identical conditions. All buffers and equipment were from BioRaD (BioRad Laboratories GmbH, Munich, Germany). Proteins were transferred to a polyvinylidene difluoride membrane (BioRad, Hercules, Calif., USA) using a semidry blotting system (Trans Turbo BLOT; BioRad). Membranes were blocked and incubated overnight at $4{ }^{\circ} \mathrm{C}$ with primary antibodies diluted in $5 \%$ 0.05 mol Tris-buffered saline (Sigma, St. Louis, Mo., USA). The following primary antibodies were used: cytochrome $c$ oxidase 
(COX IV) and succinate dehydrogenase (SDH) (both 1:2,000) (Cell Signaling, Beverly, Mass., USA), PGC-1 alpha (1:1,000) (Abcam, Cambridge, Mass., USA), phosphofructokinase (PFK; Santa Cruz Biotechnologies, Santa Cruz, Calif., USA), and mitochondrial transcription factor A (TFAM, 1:2,000) (Sigma).

a-Tubulin antibody was used as a loading control $(1: 4,000)$ [Developmental studies Hybridoma Database (DSHB), Iowa City, Iowa, USA]. This antibody is frequently used as reliable loading control in resistance-exercised skeletal muscle [17, 18].

Secondary antibodies (HRP-linked goat anti-rabbit and goat anti-mouse; Cell Signaling, Beverly, Mass., USA) were diluted 1: 8,000 in $0.05 \mathrm{~mol}$ TBS-T containing 5\% milk. Membranes were incubated at room temperature under constant agitation for $1 \mathrm{~h}$. Proteins were detected by an enhanced chemo-luminescence assay (ECL Kit, Amersham Life Science, Little Chalfont, UK) exposed to X-ray film (Kodak X-OMAT Engineering, Eastman Kodak Co., Rochester, N.Y., USA). All Western blots were quantified via densitometry using Image ${ }^{\circledR}$ software (National Institutes of Health, Bethesda, Md., USA).

\section{Analysis}

All data were analysed using PASW Statistics 18.0 (Chicago, Ill., USA) and are presented as the mean \pm standard deviation or median (95\% confidence interval), unless otherwise noted. Power calculation was not performed prior to the study. The reason is that the literature on skeletal muscle function and/or the properties in COPD patients with or without A1ATD is not available. Therefore, sample size was orientated towards studies including skeletal muscle biopsies of COPD patients which resulted in significant outcomes based on $7-11$ patients per group $[7,19,20]$. The non-parametric Wilcoxon test was used to assess changes in fibre type distribution, capillarisation and proteins. To compare PiZZ with PiMM patients, unpaired t tests were used when the distribution was normal (validated using the Kolmogorov-Smirnov test). To explore relations between the change in myofibre type I proportion and possible measured variables, univariate Person correlation analysis was performed. Variables that were associated with delta myofibre type I were included in a forward multiple regression analysis.

\section{Results}

\section{Study Subjects}

Baseline characteristics of 19 patients are presented in table 1. Both groups were comparable regarding their lung function impairment. Baseline $\mathrm{pCO}_{2}$ values were significantly higher in PiMM than in PiZZ patients. Out of 9 PiZZ patients, 6 received specific alpha- 1 antitrypsin (A1AT) therapy (Prolastin ${ }^{\circledR}$; Grifols, Spain). Participants were instructed to wear the physical activity monitors 24 h/day for 5 consecutive days during the PR program. Mean daily energy expenditure (PiZZ: 2,568 $\pm 523 \mathrm{cal}$ and PiMM: 2,235 \pm 438 cal, $\mathrm{p}=$ n.s.) and mean steps per day (PiZZ: 7,776 \pm 4,078 and PiMM: 5,858 \pm 3,420, $\mathrm{p}=$ n.s.) were comparable in both groups.

Skeletal Muscle Adaptations in Alpha-1 Antitrypsin Deficiency COPD Patients
Table 1. Baseline characteristics

\begin{tabular}{|c|c|c|c|}
\hline & \multicolumn{2}{|c|}{ COPD patients } & \multirow[t]{2}{*}{$\mathrm{p}$ value } \\
\hline & $\begin{array}{l}\text { PiZZ } \\
(n=9)\end{array}$ & $\begin{array}{l}\text { PiMM } \\
(\mathrm{n}=10)\end{array}$ & \\
\hline Males, $\mathrm{n}$ & $6(67 \%)$ & $6(60 \%)$ & 0.764 \\
\hline Age, years & $56(7)$ & $62(7)$ & 0.078 \\
\hline BMI & $24.2(2.7)$ & $23.3(4.1)$ & 0.583 \\
\hline $\mathrm{FEV}_{1}, \%$ predicted & $32.9(8.9)$ & $28.3(3.8)$ & 0.153 \\
\hline $\mathrm{FEV}_{1}, 1$ & $1.1(0.4)$ & $0.8(0.2)$ & 0.065 \\
\hline $\mathrm{DLCO}, \mathrm{mmol} / \mathrm{min} / \mathrm{kPa}$ & $32.9(8.9)$ & $29.2(19)$ & 0.326 \\
\hline $\mathrm{PaO}_{2}, \mathrm{~mm} \mathrm{Hg}$ & $58.3(4.8)$ & $57.2(7.0)$ & 0.702 \\
\hline $\mathrm{PaCO}_{2}, \mathrm{~mm} \mathrm{Hg}$ & $36.7(2.4)$ & $43.8(5.0)$ & $<0.001$ \\
\hline A1AT substitution therapy, $\mathrm{n}$ & $6(67 \%)$ & 0 & - \\
\hline Physical activity level $^{\mathrm{a}}$ & $1.71(0.30)$ & $1.63(0.25)$ & 0.510 \\
\hline
\end{tabular}

Values are mean $(\mathrm{SD})$ unless otherwise noted. $\mathrm{FEV}_{1}=$ Forced expiratory volume in $1 \mathrm{~s}$; DLCO = diffusion capacity of the lung for carbon monoxide; $\mathrm{PaO}_{2}=$ partial pressure of oxygen; $\mathrm{PaCO}_{2}=$ partial pressure of carbon dioxide. ${ }^{\text {a }}$ Total energy expenditure in a 24 -hour period divided by the basal metabolic rate (measured by SenseWear Armband ${ }^{\circledR}$ ).

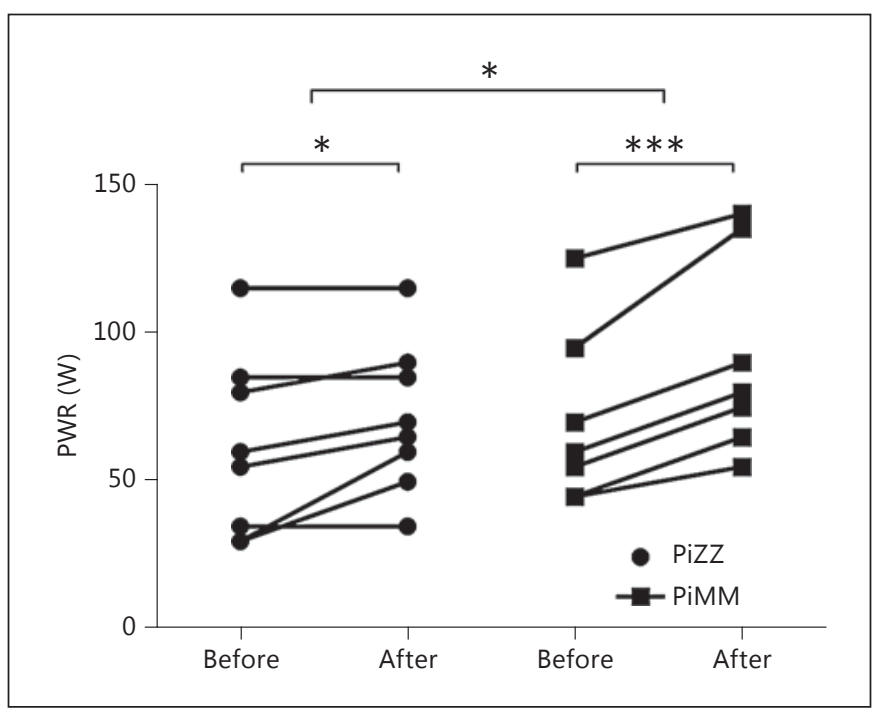

Fig. 1. PWR. Improvements of PWR due to 3 weeks of PR in 9 PiZZ and 10 PiMM patients.

\section{Training Program and Exercise Capacity}

PiZZ and PiMM patients completed similar PR exercise training programs. Endurance training workload (intensity $\times$ duration) and mean training intensity (85 \pm 21 and $84 \pm 16 \mathrm{~W}$ ) did not differ between groups. 


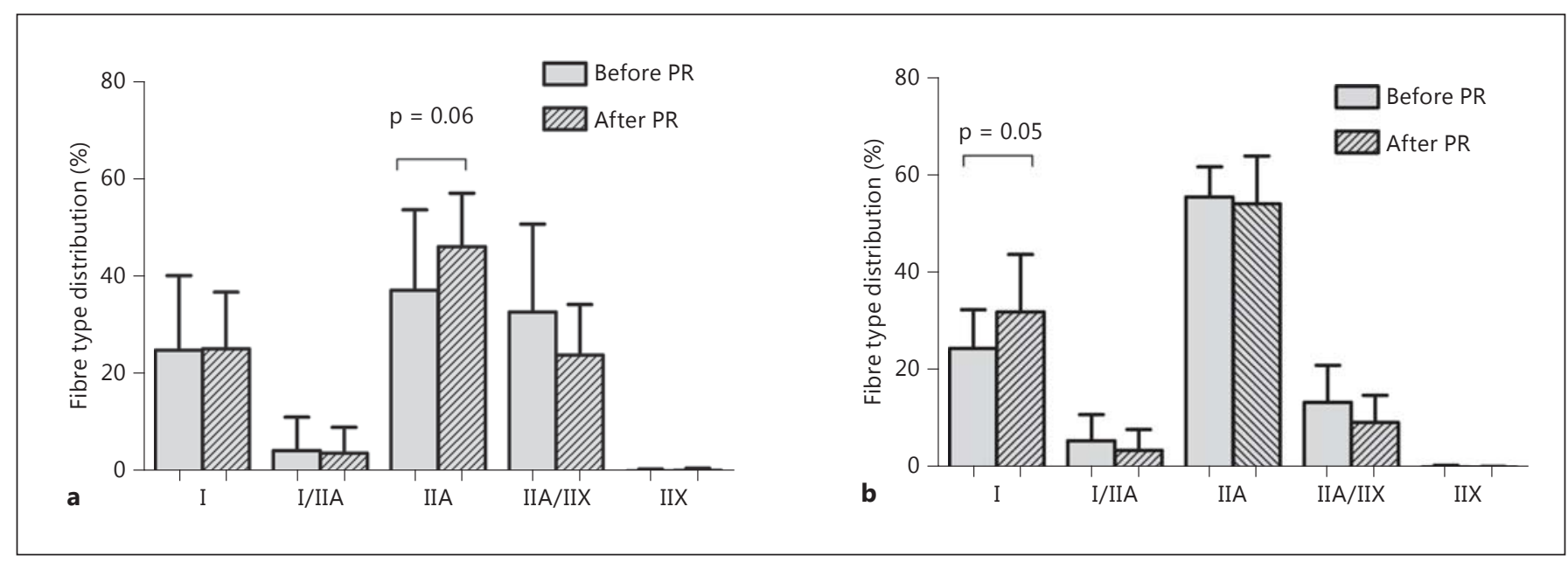

Fig. 2. Muscle fibre type distribution. Myofibre type distribution before and after PR training in 9 PiZZ (a) and $10 \mathrm{PiMM}$ (b) patients.

Table 2. Morphological baseline data

\begin{tabular}{|c|c|c|c|c|}
\hline & \multicolumn{2}{|c|}{ COPD patients } & \multirow{2}{*}{$\begin{array}{l}\text { Between-group } \\
\text { difference }\end{array}$} & \multirow[t]{2}{*}{$\mathrm{p}$ value } \\
\hline & $\operatorname{PiZZ}(\mathrm{n}=9)$ & $\operatorname{PiMM}(\mathrm{n}=10)$ & & \\
\hline \multicolumn{5}{|c|}{ Myofibre type distribution (\%) } \\
\hline Type I & $25.0(15.3)$ & $24.5(8.6)$ & $0.5[-13.3$ to 14.4$]$ & 0.937 \\
\hline Type I/IIa & $4.6(6.8)$ & $5.8(5.8)$ & $-1.2[-8.1$ to 5.7$]$ & 0.706 \\
\hline Type IIa & $37.3(16.4)$ & $57.0(5.1)$ & $-19.7[-33.6$ to -5.8$]$ & $<0.01$ \\
\hline Type IIa/IIx & $32.8(18.0)$ & $12.2(7.0)$ & $20.6[5.1$ to 36.1$]$ & $<0.05$ \\
\hline Type IIx & $0.4(0.4)$ & $0.4(0.3)$ & $-0.0[-0.4$ to 0.4$]$ & 0.895 \\
\hline \multicolumn{5}{|l|}{ CFR } \\
\hline Type I & $3.6(1.3)$ & $3.6(1.6)$ & $0.01[-1.6$ to 1.6$]$ & 0.988 \\
\hline Type II & $3.1(1.0)$ & $3.0(1.1)$ & $0.03[-1.1$ to 1.2$]$ & 0.960 \\
\hline
\end{tabular}

Values are mean $(\mathrm{SD})$ or median $[95 \% \mathrm{CI}]$.

Exercise capacity at baseline, measured by the 6-min walk distance (6MWD) and the PWR, did not differ significantly between PiZZ and PiMM patients. Both groups increased 6MWD to a comparable extent (PiZZ: $+29 \pm$ $28 \mathrm{~m}, \mathrm{p}<0.05$, PiMM: $+31 \pm 44 \mathrm{~m}, \mathrm{p}=0.05)$. PWR improved by $9 \pm 11 \mathrm{~W}$ in PiZZ vs. $18 \pm 19 \mathrm{~W}$ in PiMM patients (between-group difference: $\mathrm{p}<0.05$ ) (fig. 1).

\section{Fibre Type Distribution and Capillarisation}

A summary of baseline morphological data is shown in table 2. At the beginning of PR, the percentage of oxidative type I fibres was similar in PiZZ (25.0 $\pm 15.3 \%)$ and PiMM patients $(24.5 \pm 8.6 \%)$. At baseline, there was a cor- relation between the proportion of myofiber type I and $6 \mathrm{MWD}(\mathrm{r}=0.714, \mathrm{p}<0.01)$. Following PR training, fibre type I levels did not change in PiZZ $(-0.3 \pm 16.2 \%$, $\mathrm{p}=$ $0.964)$ but slightly increased in PiMM patients $(+8.1 \pm$ $9.0 \%, \mathrm{p}=0.054)$. On the other hand, PiZZ patients increased the proportion of more glycolytic myofibre type IIA $(+8.9 \pm 11.8 \%, \mathrm{p}=0.055)$ and slightly decreased the percentage of hybrid fibre types IIA/IIX $(-8.8 \pm 18.6 \%$, $\mathrm{p}=0.193)$. In contrast, PiMM patients reduced the proportion of fibre type IIA $(-2.1 \pm 7.7 \%, \mathrm{p}=0.09)$ and IIA/ IIX $(-3.9 \pm 5.1 \%, p=0.09)$ (fig. 2). Concerning the sum of glycolytic type II fibres (I/IIA, IIA, IIA/IIX and IIX), no changes were found in PiZZ patients $(-0.3 \%, \mathrm{p}=$ 


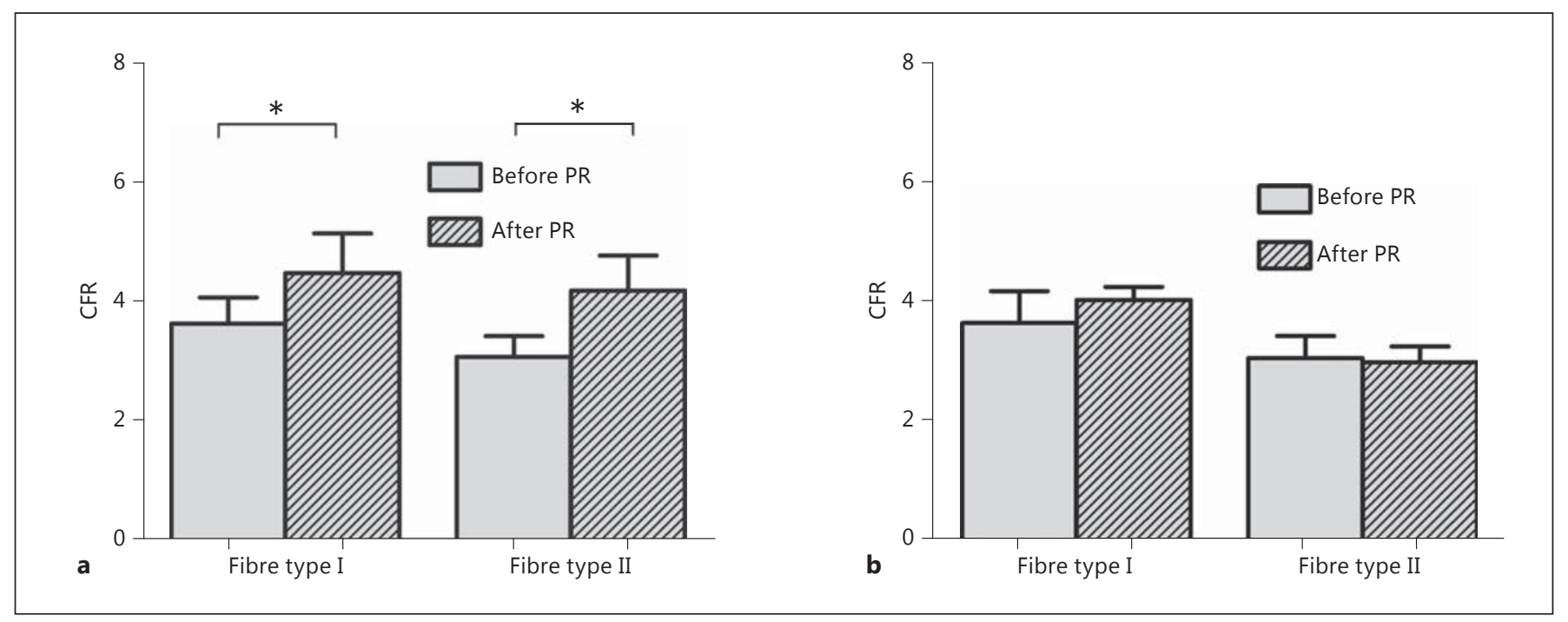

Fig. 3. Myofibre capillarisation. Capillarisation of myofibre types I and II before and after PR training in 9 PiZZ (a) and 10 PiMM (b) patients. Capillarisation of myofibre types I and II increased significantly in PiZZ but not in PiMM patients.

0.954) after PR. In contrast, these fibres showed the tendency to decrease in PiMM patients $(-8.0 \%, \mathrm{p}=0.055)$.

The CFR did not differ between groups. After PR, the CFR of fibre type I and II increased in PiZZ patients $[+0.9$ \pm 0.8 CFR $(+25 \%)$ and $+1.1 \pm 1.2$ CFR $(+35 \%), \mathrm{p}<0.05$, respectively], whereas no significant changes were found in PiMM patients $[+0.4 \pm 1.5 \mathrm{CFR}(+11 \%), \mathrm{p}=0.55$ and $-0.2 \pm 1.4$ CFR (-7\%), $\mathrm{p}=0.78$ ] (fig. 3).

\section{Metabolic Enzymes and Mitochondrial Signalling}

Following PR, no significant changes occurred in the levels of COX IV, an indicator of oxidative capacity [17], or SDH an enzyme of the citric cycle and electron transport chain [18] among PiMM and PiZZ patients. PFK, a key enzyme in glycolysis [19], was reduced in both groups, but statistical significance was found only in the PiMM group (PiZZ: $-0.5 \pm 1.2, \mathrm{p}=0.233$, PiMM: $-0.2 \pm 0.3, \mathrm{p}=$ $0.05)$. The levels of proliferator-activated receptor- $\gamma$ coactivator-1 $\alpha$ (PGC-1 $\alpha$ ), a controller of mitochondrial biogenesis $[20,21]$ and TFAM, a key activator of mitochondrial transcription [22], increased in PiMM (PGC$1 \alpha$ : 4.5-fold, $\mathrm{p}<0.05$; TFAM: 6.4-fold, $\mathrm{p}<0.05)$ but remained unchanged in PiZZ patients (PGC-1 $\alpha$ : 1.8-fold, $\mathrm{p}=0.903$; TFAM: 1.7 -fold, $\mathrm{p}=0.351$ ) (fig. 4).

\section{Predictors of Myofibre Type I Response due to PR \\ Training}

Variables related to the change of myofibre type I in the univariate analysis are presented in table 3 . In the best-fit multiple regression analysis equation, the diffusion capacity of the lung and A1AT augmentation therapy are predictors for myofibre type I changes in response to PR. Indeed, patients with lower diffusion capacity and without A1AT therapy showed the highest increase in fibre type I proportion after PR. This model explains $82.2 \%$ of the variance of the change in myofibre type I proportion $\left(\mathrm{r}^{2}=0.822, \mathrm{p}<0.001\right)$.

\section{Discussion}

Our results demonstrate that $\mathrm{PR}$ is beneficial to PiZZ and PiMM patients. However, despite the fact that training conditions were similar for PiMM and PiZZ patients, PiMM improved exercise capacity better than PiZZ. This finding was mirrored by the different exercise-induced adaptation pattern in skeletal muscle. Following PR, PiMM patients increased the percentage of oxidative and fatigue-resistant myofibre type I, whereas PiZZ patients increased the percentage of glycolytic myofibre type IIA. Similarly, mitochondrial signalling proteins, such as PGC1 $\alpha$ and TFAM, increased only in PiMM patients. Moreover, PiZZ but not PiMM patients showed a positive adaptation in capillarisation. Altogether, the best response to $\mathrm{PR}$ by increasing myofibre type I proportion could be achieved in COPD patients having lower diffusion capacity and were not treated with A1AT augmentation therapy. 


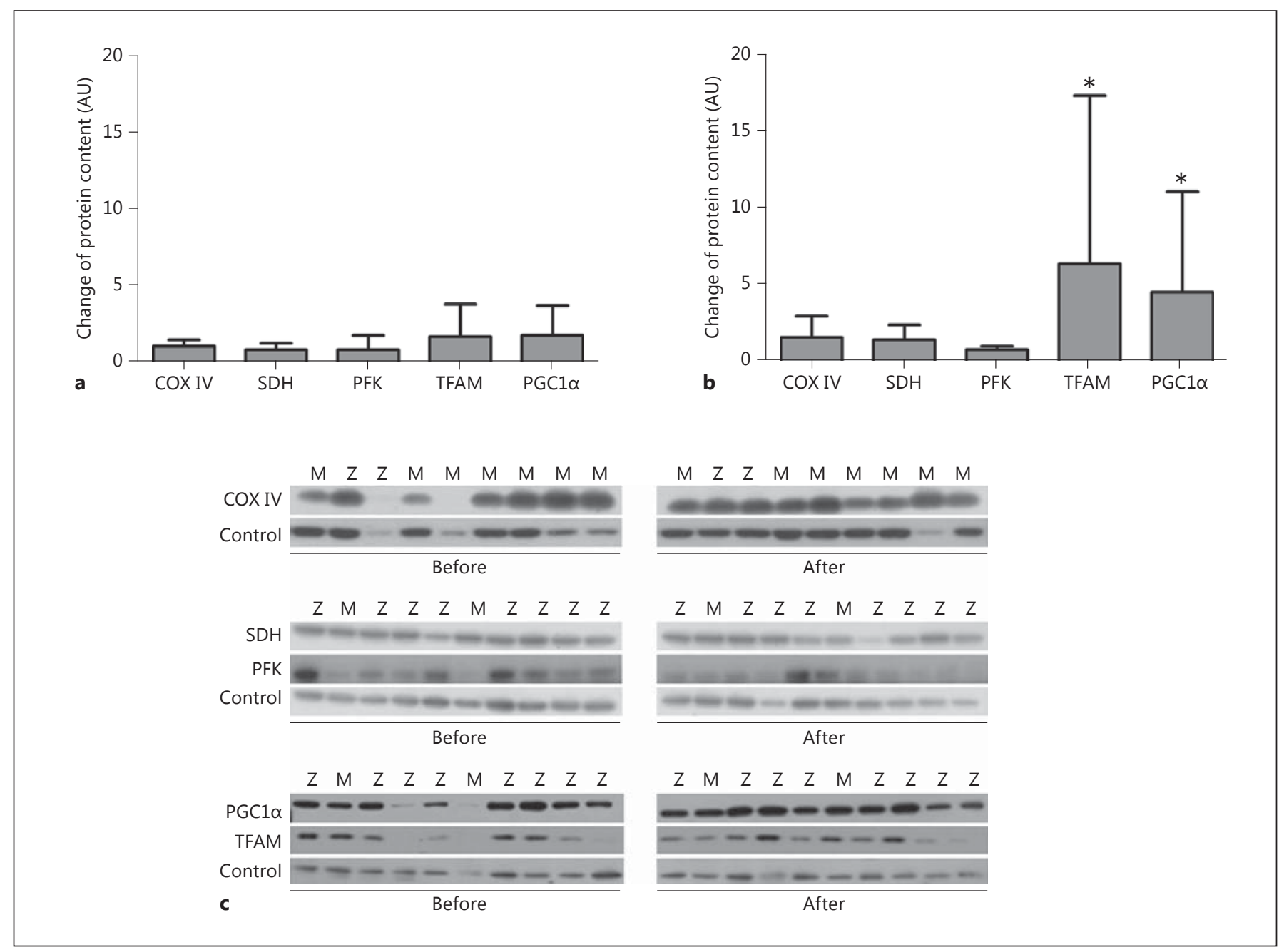

Fig. 4. Protein content. Western blotting analysis showed the change of energy metabolism key proteins COX IV, $\mathrm{SDH}$ and PFK, and mitochondrial signalling parameter (PGC1 $\alpha$ and TFAM) due to PR training in 9 PiZZ (a) and 10 PiMM (b) COPD patients. TFAM and PGC1 $\alpha$ increased significantly due to PR training in PiMM ( $p<$ 0.05) but remained unchanged in PiZZ patients. c Some representative blots for COX IV, SDH, PFK, PGC1 $\alpha$, and TFAM (control: tubulin) from 10 PiMM and 9 PiZZ patients are shown.

Skeletal muscle dysfunction in COPD patients is characterised by a decrease in the proportion of oxidative type I fibres and a shift toward fibre type II with lower oxidative capacity, an attenuation of mitochondrial enzyme expression, and a significant loss of capillary density $[3,21]$. Similarly, COPD patients in our cohort had low baseline counts of type I ( $25 \%)$ and high baseline counts of type II fibres ( 75\%), displayed as IIA, IIX and IIA/IIX hybrid fibres. Therefore, the major goal of PR training is to reduce these skeletal muscle impairments and to improve oxidative capacity that enables patients to perform daily physical activity.
We would like to emphasise that a 3-week inpatient PR program including exercise training, education and behaviour change, is accepted in specialised German rehabilitation centres. Although inpatient PR programs have a shorter duration, they typically result in improvements of physical performance [22]. In support of the latter, both groups in our study reached the threshold for clinically relevant improvements in exercise capacity (6MWD $>25-33 \mathrm{~m}$ [23] and PWR >4 W) [24]. Also, our morphological data agree with the findings of a previous study showing a $6.6 \%$ increase in the proportion of fibre type I in non-cachectic COPD patients after a 10 -week exercise training program [25]. 
Table 3. Pearson correlation coefficients reaching statistical significance $(\mathrm{p}<0.05)$ between the change in myofibre type I proportion following PR and other potential explaining factors measured

\begin{tabular}{lll}
\hline & \multicolumn{2}{l}{$\begin{array}{l}\text { Correlation coefficient with } \\
\Delta \text { fibre type I (\%) }\end{array}$} \\
\cline { 2 - 3 } & Coefficient r & p value \\
\hline FEV $_{1}(\%$ predicted) & -0.648 & 0.007 \\
Physical activity level $^{\text {a }}$ & -0.527 & 0.043 \\
Myofibre type I proportion (\%) & -0.566 & 0.022 \\
DLCO (mmol/min/kPa) & -0.740 & 0.002 \\
6MWD (m) & -0.536 & 0.032 \\
A1AT therapy (yes/no) & -0.678 & 0.004 \\
\hline
\end{tabular}

$\mathrm{FEV}_{1}=$ Forced expiratory volume in $1 \mathrm{~s}$; DLCO $=$ diffusion capacity of the lung for carbon monoxide. a Total energy expenditure in a 24-hour period divided by the basal metabolic rate (measured by SenseWear Armband ${ }^{\circledR}$ ).

The increase in the percentage of myofibre type I proportion was described in healthy subjects after sufficient training periods with various training modalities [26]. Therefore, we also expected this adaptation in our study cohort. As predicated, after PR training an increase in myofibre type I proportion occurred in PiMM patients. In contrast, however, a positive adaptation in type IIA but not in type I fibres was observed in PiZZ patients. Type IIA fibres are less oxidative, more fatigue-prone and have a significantly higher energy consumption compared to type I fibres. A significant correlation between the baseline value of $6 \mathrm{MWD}$ and myofibre type I proportion suggests that the unchanged proportion of type I fibres in PiZZ patients may reflect smaller adaptations in endurance capacity and higher muscle fatigability that limits physical activity.

A reduction in hybrid fibre type IIA/IIX distribution in healthy subjects is assumed to be a result of a successful training program [26]. The patients in our study did not show significant reduction in this fibre type. This finding is in line with another study by Gouzi et al. [27] showing that a 6-week PR with exercise training in COPD patients did not result in a significant reduction of myofibre type IIA/IIX. A short PR duration (of 3-6 weeks) probably is not sufficient to induce significant adaptations in hybrid fibres.

With regard to the protein analysis, the levels of COX IV and SDH that are involved in oxidative muscle energy metabolism did not increase in either group. The reason might be that these proteins could not be sufficiently accumulated with the low exercise volume and/or the short time period of our PR program. However, the content of PFK, a glycolytic key protein in energy metabolism, decreased in PiMM but not PiZZ patients. In line with this, mitochondrial signalling parameters of PGC-1 $\alpha$ and TFAM were significantly increased in PiMM but not in PiZZ patients. The expression of PGC-1- $\alpha$ and TFAM depends on the abundance of mitochondria in oxidative fibre type I in skeletal muscle. PGC-1a enhances the shift in fibre composition to a more oxidative fibre type [28]. This further supports the augmented expression of oxidative type I fibre and oxidative adaptation pattern in PiMM but not in PiZZ patients. Altogether, the above-described differences in skeletal muscle adaptation patterns may explain, at least partially, the lower improvement of PWR in PiZZ patients observed after the 3-week PR.

To find predictors for the best oxidative adaptation related to PR, we performed a multiple regression analysis. Results revealed that patients with lower diffusion capacity values and those without A1AT therapy show the highest increase in myofibre type I proportion. The latter indicates that patients with a more impaired condition and more severe disease stages benefit more from PR training than healthier patients. Intravenous infusion of the A1AT protein is a specific augmentation therapy for PiZZ COPD patients. The therapy is typically used in patients who have moderate emphysema $\left(\mathrm{FEV}_{1}, 30-65 \%\right.$ predicted) and is usually continued indefinitely. Clinical studies demonstrate that A1AT therapy reverses the biochemical abnormalities of the A1AT protein in serum and lung fluid, and reverses the decline in lung density [29-31]. It has been shown that the specific A1AT preparation used in our patients (Prolastin ${ }^{\circledR}$ ) contains significant quantities of fatty acids. Fatty acid-bound A1AT was found to upregulate the expression and release of angiopoietin-like protein 4 (angptl4) [29]. angptl4 is a potent inhibitor of the lipoprotein lipase (LPL), an enzyme hydrolysing triglycerides [30]. By coordinating lipid uptake in exercising and non-exercising muscles, angptl4 seems to play an important role in LPL-dependent clearance of triglycerides in skeletal muscle, particularly during acute exercise, and potentially contributes in maintaining oxidative muscle fibre expression [31]. Hence, the decreased activity of LPL in human skeletal muscle may blunt the expression of peroxisome proliferator-activated receptor (PPAR), which interacts with PGCla and regulates oxidative fibre expression and mitochondrial biogenesis [28]. For example, in the skeletal muscle of diabetic patients, a decreased expression of LPL was associated with 
reduced mitochondrial density due to the reduced PPAR signalling. We found significantly increased PGC1a protein in PiMM, but not in PiZZ patients. Given that the oxidative muscle regions normally have the greatest amount of LPL activity, oxidative muscle fibre type I adaptation might be blunted in augmented PiZZ patients receiving Prolastin ${ }^{\circledR}$ therapy resulting from increased angptl4 expression [32]. Further studies are required to confirm this hypothesis.

Endurance training in general has been shown to induce angiogenesis and increase CFR in healthy subjects, indicating an improvement of oxygen transport capacity to working muscle fibres. It is known that capillarisation in type I and II improves equally to exercise training at moderate intensities [33]. Healthy subjects reported an increase of $20 \%$ capillarisation after 8 weeks of bicycle training at $80 \%$ of $\mathrm{VO}_{2 \max }$; results are less pronounced in COPD patients after 6 weeks training $(+16 \%)[27,33]$. Across our study population, the mean CFR increased by $17.9 \%$. It is considerable that only COPD patients with the PiZZ genotype showed a positive adaptation of muscle fibre capillarisation $(+25 \%$ in type I and $+35 \%$ in type II).

The major limitation of our study is a small sample size. This is related not only to the difficulties to recruit well-matched PiMM and PiZZ patient groups but also to the ethical problems, as many patients will not be able or do not agree to donate large muscle biopsies. Therefore, the changes in myofibre type I proportion, used as the primary outcome, did not reach statistical significance (training-induced differences between groups: $+8.1 \% \pm$ 9.0 in PiMM vs. $-0.3 \% \pm 16.2$ in PiZZ patients). On the other hand, the standard deviation was very high within the PiZZ group. Noticeably, when considering only those PiZZ patients who were augmented with A1AT therapy $(n=6)$ and comparing them to PiMM patients, variance becomes smaller and the between-group difference in adaptation of myofibre type I proportion reached significance $(-7.9 \% \pm 11.7$ vs. $+8.1 \% \pm 9.0 ; p=0.01)$. Data in- volving a large cohort of patients are needed to confirm our findings.

In conclusion, COPD patients with the PiZZ and PiMM genotypes of A1AT elicit distinct changes in skeletal muscle adaptations after 3 weeks of PR with similar training conditions. In clinical practice, no disease-specific training modalities are available for COPD patients with different genotypes. Also, the role of A1ATD-specific pharmacotherapy in exercise-induced skeletal muscle adaptation has to be clarified in further studies in order to improve exercise training programs for PiZZ patients and achieve an optimum response to PR.

\section{Acknowledgements}

\section{Recognition of Non-Authors}

The authors thank Dr. Rainer Glöckl (Schön Klinik BGL, Germany) for his ideas implemented in the exercise training protocol and PD Dr. Thorsten Schiffer (German Sport University Cologne, Germany) for his support with muscle biopsies. We also would like to thank all teams in the Department of Respiratory Medicine (Schön Klinik BGL, Schönau, Germany) for assisting with the logistics of the study and their contribution to this work. We acknowledge the students of the German Sport University Cologne for their analyses in the laboratory.

\section{Funding Information}

The study was partly supported by the European Alpha1 Foundation (Cologne, Germany) and Talecris Biotherapeutics $\mathrm{GmbH}$ (Frankfurt am Main, Germany). Neither of the supporting sources had any influence on the study design, data collection, data analysis and interpretation, the writing of the manuscript, and the decision to submit the manuscript for publication.

\section{Financial Disclosure and Conflicts of Interest}

I.J., S.G., D.J., R.A.K., W.B., S.J. have no conflicts of interest to disclose. K.K. reports grants from Talecris Biotherapeutics and grants from Alpha 1 Foundation Europe during the conduct of the study. M.W. is a former employee of Talecris. T.W. reports grants from Grifols during the conduct of the study.
References
1 Gosker HR, Zeegers MP, Wouters EF, Schols AM: Muscle fibre type shifting in the vastus lateralis of patients with COPD is associated with disease severity: a systematic review and meta-analysis. Thorax 2007;62:944-949.

2 Whittom F, Jobin J, Simard PM, Leblanc P, Simard C, Bernard S, et al: Histochemical and morphological characteristics of the vastus lateralis muscle in patients with chronic ob- structive pulmonary disease. Med Sci Sports Exerc 1998;30:1467-1474

3 Maltais F, Decramer M, Casaburi R, Barreiro E, Burelle Y, Debigare R, et al: An official American Thoracic Society/European Respiratory Society statement: update on limb muscle dysfunction in chronic obstructive pulmonary disease. Am J Respir Crit Care Med 2014;189:e15-e62. 
4 Spruit MA, Singh SJ, Garvey C, ZuWallack R, Nici L, Rochester C, et al: An official American Thoracic Society/European Respiratory Society statement: key concepts and advances in pulmonary rehabilitation. Am J Respir Crit Care Med 2013;188:e13-e64.

5 Osadnik CR, Rodrigues FM, Camillo CA, Loeckx M, Janssens W, Dooms C, et al: Principles of rehabilitation and reactivation. Respiration 2015;89:2-11.

6 Man WD, Kemp P, Moxham J, Polkey MI: Exercise and muscle dysfunction in COPD: implications for pulmonary rehabilitation. Clin Sci (Lond) 2009;117:281-291.

7 Vogiatzis I, Terzis G, Nanas S, Stratakos G, Simoes DC, Georgiadou O, et al: Skeletal muscle adaptations to interval training in patients with advanced COPD. Chest 2005;128: 3838-3845.

8 Wittmann M, Stojanovic K, Schultz K: Effectiveness of a 3-week in-patient rehabilitation program in patients with COPD GOLD stage IV. Eur Respir J 2013;42(suppl 54):A2221.

9 Greulich T, Koczulla AR, Nell C, Kehr K, Vogelmeier CF, Stojanovic D, et al: Effect of a three-week inpatient rehabilitation program on 544 consecutive patients with very severe COPD: a retrospective analysis. Respiration 2015;90:287-292.

10 Seersholm N, Kok-Jensen A: Clinical features and prognosis of life time non-smokers with severe alpha 1-antitrypsin deficiency. Thorax 1998;53:265-268.

$\checkmark 11$ Marciniuk DD, Hernandez P, Balter M, Bourbeau J, Chapman KR, Ford GT, et al: Alpha-1 antitrypsin deficiency targeted testing and augmentation therapy: a Canadian Thoracic Society clinical practice guideline. Can Respir J 2012;19:109-116.

12 Kenn K, Gloeckl R, Soennichsen A, Sczepanski B, Winterkamp S, Boensch M, et al: Predictors of success for pulmonary rehabilitation in patients awaiting lung transplantation. Transplantation 2015;99:1072-1077.

13 Gloeckl R, Heinzelmann I, Baeuerle S, Damm E, Schwedhelm AL, Diril M, et al: Effects of whole body vibration in patients with chronic obstructive pulmonary disease - a randomized controlled trial. Respir Med 2012;106: $75-83$.
Rabe KF, Hurd S, Anzueto A, Barnes PJ, Buist SA, Calverley P, et al: Global strategy for the diagnosis, management, and prevention of chronic obstructive pulmonary disease: GOLD executive summary. Am J Respir Crit Care Med 2007;176:532-555.

15 ATS Statement: Guidelines for the six-minute walk test. Am J Respir Crit Care Med 2002; 166:111-117.

16 Gehlert S, Suhr F, Gutsche K, Willkomm L, Kern J, Jacko D, et al: High force development augments skeletal muscle signalling in resistance exercise modes equalized for time under tension. Pflugers Arch 2015;467:13431356.

17 Mitchell CJ, Churchward-Venne TA, Bellamy L, Parise G, Baker SK, Phillips SM: Muscular and systemic correlates of resistance traininginduced muscle hypertrophy. PLoS One 2013; 8:e78636.

18 Akimoto T, Pohnert SC, Li P, Zhang M, Gumbs C, Rosenberg PB, et al: Exercise stimulates PGC-1alpha transcription in skeletal muscle through activation of the p38 MAPK pathway. J Biol Chem 2005;280:19587-19593.

19 Bronstad E, Rognmo O, Tjonna AE, Dedichen HH, Kirkeby-Garstad I, Haberg AK, et al: High-intensity knee extensor training restores skeletal muscle function in COPD patients. Eur Respir J 2012;40:1130-1136.

20 Puente-Maestu L, Lazaro A, Tejedor A, Camano S, Fuentes M, Cuervo M, et al: Effects of exercise on mitochondrial DNA content in skeletal muscle of patients with COPD. Tho$\operatorname{rax} 2011 ; 66: 121-127$.

21 Maltais F, LeBlanc P, Simard C, Jobin J, Berube C, Bruneau J, et al: Skeletal muscle adaptation to endurance training in patients with chronic obstructive pulmonary disease. Am J Respir Crit Care Med 1996;154(2 Pt 1):442447.

22 Clini E, Foglio K, Bianchi L, Porta R, Vitacca M, Ambrosino N: In-hospital short-term training program for patients with chronic airway obstruction. Chest 2001;120:15001505.

23 Singh SJ, Puhan MA, Andrianopoulos V, Hernandes NA, Mitchell KE, Hill CJ, et al: An official systematic review of the European Respiratory Society/American Thoracic Society: measurement properties of field walking tests in chronic respiratory disease. Eur Respir J 2014;44:1447-1478.
24 Puhan MA, Chandra D, Mosenifar Z, Ries A, Make B, Hansel NN, et al: The minimal important difference of exercise tests in severe COPD. Eur Respir J 2011;37:784-790.

25 Vogiatzis I, Simoes DC, Stratakos G, Kourepini E, Terzis G, Manta P, et al: Effect of pulmonary rehabilitation on muscle remodelling in cachectic patients with COPD. Eur Respir J 2010;36:301-310.

26 Williamson DL, Gallagher PM, Carroll CC, Raue U, Trappe SW: Reduction in hybrid single muscle fiber proportions with resistance training in humans. J Appl Physiol 2001;91: 1955-1961.

27 Gouzi F, Prefaut C, Abdellaoui A, Roudier E, de Rigal P, Molinari N, et al: Blunted muscle angiogenic training-response in COPD patients versus sedentary controls. Eur Respir J 2013;41:806-814.

28 Gouspillou G, Sgarioto N, Norris B, BarbatArtigas S, Aubertin-Leheudre M, Morais JA, et al: The relationship between muscle fiber type-specific PGC-1alpha content and mitochondrial content varies between rodent models and humans. PLoS One 2014; 9:e103044.

29 Frenzel E, Wrenger S, Brugger B, Salipalli S, Immenschuh S, Aggarwal N, et al: Alpha1antitrypsin combines with plasma fatty acids and induces angiopoietin-like protein $4 \mathrm{ex}$ pression. J Immunol 2015;195:3605-3616.

30 Jonker JT, Smit JW, Hammer S, Snel M, van der Meer RW, Lamb HJ, et al: Dietary modulation of plasma angiopoietin-like protein 4 concentrations in healthy volunteers and in patients with type 2 diabetes. Am J Clin Nutr 2013;97:255-260.

-31 Catoire M, Alex S, Paraskevopulos N, Mattijssen F, Evers-van Gogh I, Schaart G, et al: Fatty acid-inducible ANGPTL4 governs lipid metabolic response to exercise. Proc Natl Acad Sci USA 2014;111:E1043-E1052.

32 Hamilton MT, Hamilton DG, Zderic TW: Exercise physiology versus inactivity physiology: an essential concept for understanding lipoprotein lipase regulation. Exerc Sport Sci Rev 2004;32:161-166.

33 Andersen P, Henriksson J: Capillary supply of the quadriceps femoris muscle of man: adaptive response to exercise. J Physiol 1977;270: 677-690. 